\title{
Heterogeneity and Redistribution: By Monetary or Fiscal Means?*
}

\author{
Peter N. Ireland ${ }^{\dagger}$ \\ Boston College and NBER
}

May 2004

\begin{abstract}
In models with heterogeneous agents, issues of distribution and redistribution jump to the fore, raising the question: which policies - monetary or fiscal - work most effectively in transferring income from one group to another? To begin answering this question, this note works through a series of examples using Townsend's turnpike model. Two basic results emerge. First, the zero lower bound on nominal interest rates often appears as an obstacle to redistribution by monetary means. Second, assumptions made about the government's ability to raise tax revenue without distortion and to discriminate between agent types in distributing that tax revenue play a large role in determining whether agents prefer to redistribute income by monetary or fiscal means.

JEL: E52, E63, H21, H23.
\end{abstract}

*Discussant's comments on Joydeep Bhattacharya, Joseph H. Haslag, and Antoine Martin's "Heterogeneity, Redistribution, and the Friedman Rule," prepared for the May 2004 conference, "Models of Monetary Economies II: The Next Generation," sponsored by the Federal Reserve Bank of Minneapolis and the University of Minnesota.

${ }^{\dagger}$ Please address correspondence to: Peter N. Ireland, Boston College, Department of Economics, 140 Commonwealth Avenue, Chestnut Hill, MA 02467-3859. Tel: (617) 552-3687. Fax: (617) 552-2308. Email: irelandp@bc.edu. I would like to thank Dirk Krueger for helpful discussions and the National Science Foundation for financial support through Grant No. 0213461. Any opinions, findings, and conclusions or recommendations expressed herein are my own and do not necessarily reflect the views of the National Bureau of Economic Research or the National Science Foundation. 


\section{Introduction}

When agents differ, issues of distribution and redistribution jump immediately to the fore. As they do in Joydeep Bhattacharya, Joseph H. Haslag, and Antoine Martin's (BHM's) excellent conference paper, "Heterogeneity, Redistribution, and the Friedman Rule." There, BHM find that in several models with heterogeneous agents, changes in the steady-state rate of money growth redistribute wealth across agents of different types; there, BHM show that these distributional effects work to make the Friedman (1969) rule for monetary contraction and zero nominal interest rates - more often than not the optimal monetary policy in models with a single representative agent — suboptimal at least according to some measures of social welfare. There, BHM unify and explain a seemingly disparate set of previous results scattered throughout the existing literature and present some new results of their own. One comes away impressed from a reading of a paper like BHM's - a paper that simultaneously accomplishes multiple goals.

Like all excellent papers in economics, however, BHM's raises new questions even as it definitively answers existing ones. In particular, BHM's results serve as important reminders that while the redistribution of income and wealth is most typically associated with fiscal policy actions, monetary policy actions also can and usually do have distributional consequences as well. Hence, BHM's study calls out for additional work that aims to jointly characterize optimal monetary and fiscal policies in settings where policymakers seek to achieve redistributional goals - additional work, in other words, that aims to extend the literature surveyed most recently by Chari and Kehoe (1999) to apply to cases where agents are heterogeneous and where the government seeks not only to raise revenue to finance an exogenously-given level of public spending but also to help some agents necessarily at the expense of others.

To help motivate this proposed extension of the existing literature as well as to highlight what some of the issues involved in pursuing such an extension might turn out to be, this note 
works through a series of examples in which different agents deliberately choose monetary and fiscal policies to achieve their own redistributional objectives. Each of these examples uses a version of Townsend's (1980) turnpike model-one of the three models studied by BHM as well as one of those originally presented in the first Models of Monetary Economies conference volume. Like BHM's paper, therefore, this note hopes to accomplish multiple goals: paying homage to the past while looking ahead to the future.

\section{The Turnpike Model}

In BHM's version of the Townsend (1980) turnpike model, agents are of two types, $E$ and $O$, in equal numbers. Type $E$ agents receive endowments consisting of one unit of the economy's consumption good during even-numbered periods $t=0,2,4, \ldots$ and zero endowments during

odd-numbered periods $t=1,3,5, \ldots$. Symmetrically, type $O$ agents receive endowments of one during odd-numbered periods and zero during even-numbered periods. Agents move in different directions along Townsend's turnpike, ruling out all but monetary trade. All agents have additively time-separable CRRA utility with discount factor $\beta \in(0,1)$ and coefficient of relative risk aversion $\rho \in(0, \infty)$. The money supply grows though equal lump-sum transfers at the constant rate $z$, which may take on positive or negative values but must be at least as large as $\beta-1$ to remain consistent with the existence of the symmetric, stationary, monetary equilibria that BHM focus their attention on.

BHM show that in any such equilibria, endowed agents - be they type $E$ for $t$ even or type $O$ for $t$ odd - consume an amount $c$ given by

$$
c=\frac{(1+z)^{1 / \rho}}{(1+z)^{1 / \rho}+\beta^{1 / \rho}},
$$

while unendowed agents consume the remaining $1-c$. An increase the rate of money growth 
$z$ reduces the volume of trade as all agents economize on their use of money as a medium of exchange. Looking out over the infinite horizon from the vantage point of period $t=0$, however, agents of different types have different preferences over $z$, since type $E$ agents receive the endowment first and type $O$ agents only later. More specifically, with $c$ given by the expression shown above, type $E$ agents prefer the value $z^{E}$ that solves

$$
\max _{z} \frac{c^{1-\rho}-1}{1-\rho}+\beta\left[\frac{(1-c)^{1-\rho}-1}{1-\rho}\right] \text { subject to } z \geq \beta-1,
$$

while type $O$ agents prefer the value $z^{O}$ that solves

$$
\max _{z} \frac{(1-c)^{1-\rho}-1}{1-\rho}+\beta\left(\frac{c^{1-\rho}-1}{1-\rho}\right) \text { subject to } z \geq \beta-1
$$

The Kuhn-Tucker conditions for these two constrained optimization problems lead to

Proposition 1 Type $E$ agents prefer $z^{E}=0$ and hence $c=1 /\left(1+\beta^{1 / \rho}\right)>1 / 2$, while type $O$ agents prefer $z^{O}=\beta-1$ and hence $c=1 / 2$. Moreover, for type $O$ agents, the constraint $z \geq \beta-1$ binds at the optimum.

In words, this first proposition says that type $E$ agents prefer that the money supply remain constant, while type $O$ agents prefer the steady monetary contraction advocated by Friedman (1969) that reduces the nominal interest rate to zero. Agents disagree, but their arguments are over the distinction between price stability and deflation- no one here likes inflation. In addition, the lower bound on money growth - corresponding to the zero lower bound on the nominal interest rate-becomes relevant for type $O$ agents, who would prefer an even more rapid monetary contraction if one could be implemented while still being consistent with the existence of a stationary monetary equilibrium. Of course, the zero nominal interest rate bound has become a topic of heated discussion lately - see Clement (2003) for instance. Most if not all of these discussions, however, focus on the zero nominal 
interest rate bound as an obstacle that interferes with the central bank's ability to fully achieve its stabilization goals; here, by contrast, the zero nominal interest rate bound works to partially foil type $O$ agents' redistributional ambitions.

The binding constraint on type $O$ 's preferred rate of monetary contraction raises the question of whether fiscal policy might work better than monetary policy as a tool for redistributing income and wealth. A second example confirms that it does, provided that fiscal policymakers have sufficient power and flexibility to skillfully implement a lump-sum tax-and-transfer scheme that successfully discriminates between agents of different types. This second example relies on the same basic turnpike model as above, but without money; instead, during each period $t=0,1,2, \ldots$, the government simply takes $1-\delta$ units of the consumption good away from each endowed agent and gives them to an unendowed agent. Hence, endowed agents now consume $c=\delta$, while unendowed agents consume $1-c=1-\delta$. Under this system of lump-sum taxes and transfers, type $E$ agents prefer the value $\delta^{E}$ that solves

$$
\max _{\delta} \frac{\delta^{1-\rho}-1}{1-\rho}+\beta\left[\frac{(1-\delta)^{1-\rho}-1}{1-\rho}\right]
$$

while type $O$ agents prefer the value $\delta^{O}$ that solves

$$
\max _{\delta} \frac{(1-\delta)^{1-\rho}-1}{1-\rho}+\beta\left(\frac{\delta^{1-\rho}-1}{1-\rho}\right)
$$

The first-order conditions for these two unconstrained optimization problems lead to

Proposition 2 Type $E$ agents prefer $\delta^{E}=1 /\left(1+\beta^{1 / \rho}\right)$ and hence $c=1 /\left(1+\beta^{1 / \rho}\right)>1 / 2$, while type $O$ agents prefer $\delta^{O}=\beta^{1 / \rho} /\left(1+\beta^{1 / \rho}\right)$ and hence $c=\beta^{1 / \rho} /\left(1+\beta^{1 / \rho}\right)<1 / 2$.

In determining their preferred fiscal policies, agents of both types solve essentially the same optimization problems as before when determining their preferred monetary policies but with the constraints lifted. Hence, this second proposition implies that while type $E$ 
agents are equally well off under their choices of monetary and fiscal policies, type $O$ agents do better with their choice of fiscal policy than with their choice of monetary policy. In these first two examples, therefore, fiscal policy appears to be more effective than monetary policy as a tool for the redistribution of income and wealth.

The fiscal policy options available to agents in the second example from above must satisfy the same stationarity and symmetry restrictions imposed on the monetary policy options in the first example. Type $E$ agents, for instance, cannot ask the government to set $\delta=1$ during even-numbered periods and $\delta=0$ during odd-numbered periods in an effort to consume the entire endowment in each and every period; instead, fiscal policy like monetary policy must treat the two agent types symmetrically. As suggested earlier, however, the second example does provide the fiscal authority with enormous power and flexibility: the power to intervene in the economy in lump-sum fashion and the flexibility to target its transfers specifically to the unendowed agents. To guard against the possibility that the case has been biased unfairly against monetary policy, the next section extends the original turnpike model to make redistribution by fiscal means more challenging.

\section{The Turnpike Model with Production}

The extended turnpike model simply replaces the alternating endowment patterns from the original specification with alternating abilities to produce output $y$ with elastically-supplied labor $h$ according to the constant-returns-to-scale technology described by $y=h$. Type $E$ agents have access to this technology during even-numbered periods $t=0,2,4, \ldots$ and type

$O$ agents have access to this technology during odd-numbered periods $t=1,3,5, \ldots$ During every period, therefore, goods must still be transferred from productive to unproductive agents via monetary or fiscal means.

In the monetary version of this extended model with production, the representative agent 
of type $E$ chooses nonnegative sequences $\left\{c_{t}^{E}\right\}_{t=0}^{\infty},\left\{h_{2 t}^{E}\right\}_{t=0}^{\infty}$, and $\left\{M_{t+1}^{E}\right\}_{t=0}^{\infty}$ for consumption, labor supply, and nominal money holdings to maximize an additively time-separable utility function that is now assumed to be logarithmic in consumption and linear in hours worked,

$$
\sum_{t=0}^{\infty} \beta^{t}\left[\ln \left(c_{t}^{E}\right)-h_{2 t}^{E}\right]
$$

with $\beta \in(0,1)$, subject to the budget constraints

$$
\frac{M_{t}^{E}+T_{t}}{P_{t}}+h_{t}^{E} \geq c_{t}^{E}+\frac{M_{t+1}^{E}}{P_{t}}
$$

for even-numbered periods $t=0,2,4, \ldots$ and

$$
\frac{M_{t}^{E}+T_{t}}{P_{t}} \geq c_{t}^{E}+\frac{M_{t+1}^{E}}{P_{t}}
$$

for odd-numbered periods $t=1,3,5, \ldots$ The representative agent of type $O$ solves the symmetric problem with even and odd-numbered periods reversed. In the budget constraints, $P_{t}$ denotes the nominal price of goods during each period $t=0,1,2, \ldots$, while $T_{t}$ denotes the equal lump-sum transfer made by the government to all agents during each period $t=$ $0,1,2, \ldots$ as it again acts to increase the total money supply at the constant rate $z \geq \beta-1$.

The Kuhn-Tucker conditions for the representative agents' problems imply that in any symmetric, stationary, monetary equilibrium, consumption $c$ and employment $h$ of each productive agent and consumption $c^{\prime}=h-c$ of each unproductive agent are all constant with

$$
\begin{gathered}
c=1, \\
h=\frac{1+z+\beta}{1+z},
\end{gathered}
$$


and

$$
c^{\prime}=h-c=\frac{\beta}{1+z} .
$$

These expressions confirm that in this extended model with production as in the original model with endowments, an increase in the steady-state rate of money growth works to reduce the volume of trade as agents economize on their use of money as a medium of exchange. In this extended model, however, an increase in the rate of money growth also reduces employment and hence the total volume of goods produced - an additional distortionary effect of inflation that is not present in the endowment economy. All agents agree that inflation has these negative effects, but as before, agents of different types disagree on the most appropriate setting for $z$ since from the vantage point of period $t=0$, type $E$ agents get to produce first and type $O$ agents only later. More specifically, with $c, h$, and $c^{\prime}$ given by the expressions shown above, type $E$ agents prefer the value $z^{E}$ that solves

$$
\max _{z} \ln (c)-h+\beta \ln \left(c^{\prime}\right) \text { subject to } z \geq \beta-1
$$

while type $O$ agents prefer the value $z^{O}$ that solves

$$
\max _{z} \ln \left(c^{\prime}\right)+\beta[\ln (c)-h] \text { subject to } z \geq \beta-1 \text {. }
$$

The Kuhn-Tucker conditions for these two constrained optimization problems lead to

Proposition 3 Type $E$ agents prefer $z^{E}=0$ and hence $c=1, h=1+\beta$, and $c^{\prime}=\beta$, while type $O$ agents prefer $z^{O}=\beta-1$ and hence $c=1, h=2$, and $c^{\prime}=1$. Moreover, for type $O$ agents, the constraint $z \geq \beta-1$ binds at the optimum.

This third proposition indicates that monetary policy preferences remain unaltered by the introduction of production into the turnpike model. Type $E$ agents still prefer a constant 
money supply and type $O$ agents still prefer the Friedman (1969) rule. And also as before, the lower bound on the money growth rate - or the zero lower bound on the nominal interest rate stymies type $O$ agents as they attempt to realize their redistributional ambitions, once again raising the question of whether fiscal policy might work better.

To put fiscal and monetary policies on a more even footing in this extended model with production, the government is no longer allowed to raise tax revenues in lump-sum fashion; instead, it must resort to a distortionary, flat-rate $\operatorname{tax} \theta$ on labor income. Along the same lines, the government is no longer permitted to target its transfers specifically to unendowed or unproductive agents; instead, it must rebate its tax revenues in the form of equal lumpsum transfers to all agents. These restrictions parallel those imposed earlier on monetary policy. The distortionary flat-rate income tax impacts disproportionately on the productive agents who supply labor, just as the distortionary inflation tax impacts disproportionately on the unproductive agents who must carry money into the period in order to consume; and the revenues raised through the income tax must be distributed to all agents in the form of equal lump-sum transfers, just as the newly-printed money must also be distributed through equal lump-sum transfers. Finally, the labor income tax rate $\theta$ is constrained to be constant, just like the constant money growth rate $z$.

In the non-monetary version of this extended model with production, the representative agent of type $E$ chooses nonnegative sequences $\left\{c_{t}^{E}\right\}_{t=0}^{\infty}$ and $\left\{h_{2 t}^{E}\right\}_{t=0}^{\infty}$ for consumption and labor supply to maximize the same utility function,

$$
\sum_{t=0}^{\infty} \beta^{t}\left[\ln \left(c_{t}^{E}\right)-h_{2 t}^{E}\right]
$$

with $\beta \in(0,1)$, subject to the budget constraints

$$
q_{t}+(1-\theta) h_{t}^{E} \geq c_{t}^{E}
$$


for even-numbered periods $t=0,2,4, \ldots$ and

$$
q_{t} \geq c_{t}^{E}
$$

for odd-numbered periods $t=1,3,5, \ldots$. The representative agent of type $O$ solves the symmetric problem with even and odd-numbered periods reversed. In the budget constraints, $q_{t}$ denotes the equal lump-sum transfer made by the government to all agents during each period $t=0,1,2, \ldots$ In equilibrium, the government's budget constraint requires that $q_{t}=(\theta / 2) h_{t}$, where $h_{t}$ is equivalently the amount of labor supplied, the amount of output produced, and the amount of income earned by each productive agent in the economy.

Focusing as usual on symmetric, stationary equilibria, the Kuhn-Tucker conditions for the representative agents' problems imply that consumption $c$ and employment $h$ of each productive agent and consumption $c^{\prime}=h-c$ of each unproductive agent are constant with

$$
\begin{gathered}
c=1-\theta, \\
h=2\left(\frac{1-\theta}{2-\theta}\right),
\end{gathered}
$$

and

$$
c^{\prime}=h-c=\theta\left(\frac{1-\theta}{2-\theta}\right) .
$$

Now under distortionary fiscal policy, an increase in the labor income tax rate $\theta$ unambiguously lowers the amount of output produced as well as the amount consumed by each productive agent. Meanwhile, an increase in $\theta$ has two offsetting effects on the amount consumed by each unproductive agent. Holding the tax base constant, a higher tax rate means more tax revenues, hence larger fiscal transfers to all agents including those who are unproductive. But as the tax base gets eroded by the the same increase in $\theta$, tax revenues 
fall, reducing the size of the fiscal transfers to unproductive agents. The expression for $c^{\prime}$ indicates that the first effect dominates for low values of $\theta$, while the second effect dominates for high values of $\theta$, so that consumption of unproductive agents first increases then decreases as the tax rate $\theta$ rises from zero to one.

Once again, agents of different types disagree on the optimal setting for the tax rate $\theta$ at period $t=0$, since from that vantage point type $E$ agents produce first and type $O$ agents only later. More specifically, with $c, h$, and $c^{\prime}$ given by the expressions above, type $E$ agents prefer the value $\theta^{E}$ that solves

$$
\max _{\theta} \ln (c)-h+\beta \ln \left(c^{\prime}\right)
$$

while type $O$ agents prefer the value $\theta^{O}$ that solves

$$
\max _{\theta} \ln \left(c^{\prime}\right)+\beta[\ln (c)-h]
$$

The first-order conditions for these two optimization problems fail to provide closed-form solutions for the agents' optimal choices of $\theta$, but numerical analysis reveals that with the discount factor set equal to $\beta=0.99, \theta^{E}=0.4553$ while $\theta^{O}=0.4573$. Not surprisingly, the type $E$ agents who work first prefer a slightly lower rate of labor income taxation.

Table 1 compares the values for $c$ (consumption of productive agents), $c^{\prime}$ (consumption of unproductive agents), and $h$ (total employment and output) under the two sets of monetary and fiscal policies preferred by the two sets of agents. Table 1 also compares the discounted lifetime utilities from period $t=0$ forward received by each agent type under each policy selection:

$$
U^{E}=\frac{\ln (c)-h+\beta \ln \left(c^{\prime}\right)}{1-\beta^{2}}
$$


for type $E$ agents and

$$
U^{O}=\frac{\ln \left(c^{\prime}\right)+\beta[\ln (c)-h]}{1-\beta^{2}}
$$

for type $O$ agents. All cases use the same setting of $\beta=0.99$ for the discount factor, the only parameter that needs to be calibrated in this very simple model.

Table 1 shows that replacing endowments with production reverses the earlier results: this time, monetary policies work far better than fiscal policies in redistributing income and wealth. This difference stems in large part from the strong disincentives to work that appear under flat-rate as opposed to lump-sum taxation: agents' preferred fiscal policies lead to sharp reductions in aggregate output and employment. But the government's inability to target its fiscal transfers directly and exclusively to unproductive agents surely plays an important role as well: even with tax rates in excess of 45 percent, unproductive agents consume less than 25 percent of aggregate output under the best available fiscal policy options. In this second set of examples as in the first, therefore, the results appear to hinge critically on assumptions made about how efficiently the government can intervene in the economy to raise tax revenue and how effectively the government can discriminate between agent types in redistributing that revenue.

\section{Conclusion}

Two basic results emerge from the examples considered here, all of which build on BHM's original work. First, the zero lower bound on the nominal interest rate often emerges as an obstacle to redistribution by monetary means. Second, assumptions made about the government's ability to raise tax revenue without distortion and to discriminate between agent types in distributing that tax revenue play a large role in determining whether or not agents prefer to redistribute income and wealth by fiscal means. 
A more careful and comprehensive treatment of optimal monetary and fiscal policies in environments where agents are heterogeneous and where the government may seek to achieve redistributional goals remains a big step or two further down the road. But, to be sure, BHM deserve credit —not just for the results they have obtained so far but also for pointing towards this important avenue for future research.

\section{References}

Chari, V.V. and Patrick J. Kehoe. "Optimal Fiscal and Monetary Policy." In John B. Taylor and Michael Woodford, Eds. Handbook of Macroeconomics. Amsterdam: NorthHolland, 1999.

Clement, Douglas. "Deflation: Should the Fed be Concerned?" Federal Reserve Bank of Minneapolis Region 17 (December 2003): 16-19.

Friedman, Milton. "The Optimum Quantity of Money." In The Optimum Quantity of Money and Other Essays. Chicago: Aldine Publishing Company, 1969.

Townsend, Robert M. "Models of Money With Spatially Separated Agents." In John H. Kareken and Neil Wallace, Eds. Models of Monetary Economies. Minneapolis: Federal Reserve Bank of Minneapolis, 1980. 
Table 1. Resource Allocations and Utilities Under Agents' Preferred Monetary and Fiscal Policies

$\begin{array}{llllll}\text { Monetary/Fiscal Policy } & \boldsymbol{c} & \boldsymbol{c}^{\prime} & \boldsymbol{h} & \boldsymbol{U}^{E} & \boldsymbol{U}^{O} \\ & & & & & \\ \boldsymbol{z}^{E}=\mathbf{0} & 1 & 0.99 & 1.99 & -100.5000 & -99.5050 \\ \boldsymbol{z}^{O}=-\mathbf{0 . 0 1} & 1 & 1 & 2 & -100.5025 & -99.4975 \\ \boldsymbol{\theta}^{E}=\mathbf{0 . 4 5 5 3} & 0.5447 & 0.1606 & 0.7053 & -156.9662 & -157.2257 \\ \boldsymbol{\theta}^{O}=\mathbf{0 . 4 5 7 3} & 0.5427 & 0.1609 & 0.7036 & -156.9672 & -157.2247\end{array}$

Notes: $z^{E}$ and $z^{O}$ denote the constant money growth rates preferred by type $E$ and type $O$ agents; $\theta^{E}$ and $\theta^{O}$ denote the constant labor income tax rates preferred by type $E$ and type $O$ agents. $c$ denotes consumption by productive agents, $c^{\prime}$ denotes consumption by unproductive agents, and $h$ denotes total output and employment. $U^{E}$ and $U^{O}$ denote the discounted lifetime utilities from period $t=0$ forward of type $E$ and type $O$ agents. All cases set $\beta=0.99$. 